\section{ANTI-VENEREAL MEASURES IN SCANDINAVIA}

\author{
BY
}

MARGARET RORKE, M.B., Ch.B., M.C.o.G. Consultant in Venereal Diseases to the Royal Free Hospital, London

A Commission on Venereal Diseases, approved by Sir Kingsley Wood, the then Minister of Health, left London on July 12, 1937, to visit Scandinavia. The object was to investigate conditions following notification and treatment of venereal diseases in those countries, as the fall in the number of cases in Scandinavia of recent years had seemed to be striking compared with the number of cases returned to the Ministry of Health in this country as under treatment for venereal diseases.

In the three Scandinavian countries visited-Sweden, Norway, and Denmark - a system of partial or of complete notification of these diseases in common with notification of the other ordinary infectious diseases is in force. It was thought that interest and value would be added to the Commission's report* by a visit to a country where there was no system of notification. Holland was accordingly chosen for this purpose. The fall in the number of cases under treatment, or at least of acute cases admitted to hospital, in Scandinavia seems to be very marked during the summer months. June, July, and August are the holiday months for the great mass of the people, and a migration to the country during most of this period is an outstanding feature of Scandinavian life. Not only do the rich leave the towns during these months but professional and business people's wives and children to a great extent do so, too, living simply in cottages and tiny bungalows, almost entirely in the open air by day. The workingclass population, where possible, do the same. Many encampments of tents are seen, where working-class women and children live, and where the menfolk return from work on bicycles in the evening, or, if the encampment is too far distant for that, at the week-ends. This is in accord with what seems to be the disposition of the people generally. Their winters are long and dark, and they desire, therefore, to gain the utmost from the sunshine and fresh air during the months of good weather. This is not only for enjoyment, but because they are all "health-conscious" without being in the least neurotic. This attitude towards health matters seems general and applies to venereal diseases as well as to any other illness.

\section{Attitude of the People}

The impression formed is that there is not the same sense of shame and necessity for secrecy as regards venereal disease in Scandinavia as still exists in England. The desire to be cured and to attend for treatment as long as is necessary is quite general. The whole attitude towards sex matters in Scandinavia is "modern" and matter-of-fact. One public health official of a large city has been heard to state that he was strongly in favour of condoms being supplied in automatic machines. "It is late at night when the young people return from the country that they require these things, and the chemists' shops are closed then."

The Scandinavian people as a whole are well educated in all health matters and appear to have the utmost respect for, and confidence in, their medical advisers. This is undoubtedly not only due to the equable disposition of the patients themselves but is fostered by the prolonged and thorough medical training necessary before qualification. A period of at least eight years as a medical student is the usual time for training, and in addition "specialists" have to study their subject for some years and to pass examina-

* Anti-venereal Measures in Certain Scandinavian Countries and Holland. Reports on Public Health and Medical Subjects. No. 83. H.M. Stationery Office. 2s. 6d. tions in that subject before being accredited in the specialty. This undoubtedly accounts in some measure for the very great confidence shown by patients, though no doubt the knowledge that they are bound to attend till treatment is finished must play some part.

\section{Clinics for Venereal Disease}

In various centres in the cities the policlinics are arranged not only as departments of hospitals but also in the city itself. In some cases the policlinics for venereal disease may be situated in large municipal buildings, where child welfare, gymnastics, sunlight therapy, baths, etc., are also in use, so that no patient entering the building would be obviously attending the venereal department. In some places also smaller policlinics are situated in flats in ordinary blocks of business flats; and again, save to other patients in the waiting-rooms, it would not be obvious on entering the building that the patient was attending for the treatment of venereal disease.

Almost without exception these clinics are modern in equipment and furnishing, and spotless with white paint (even benches being white-enamelled). Flowering plants give a gay air and add a domestic touch. The medical, nursing, and clerical staffs are quick, efficient, and friendly. The waiting patients in turn are ready to spring up and go in immediately a light or a bell indicates that the doctor or nurse is ready for the next patient. This, so far as women at least are concerned, is a welcome change compared with conditions in England, where so often valuable time is wasted by patients not being ready when called upon.

\section{Treatment}

The treatment of gonorrhoea does not compare favourably with that in the teaching hospitals here; but the tests of cure in Sweden and Denmark are prolonged and are undertaken at long intervals after "cure" is believed to have been achieved, and so good results are obtained. In this, of course, the element of compulsion no doubt plays a part in the patients' ready acquiescence when called upon to attend. The treatment of syphilis seems on the whole to be more protracted than in this country, but less arsphenamine is used. Almost continuous bismuth therapy for the whole of the second year of treatment is the usual rule in cases of early syphilis with persistently negative serological tests after two synchronous courses of bismuth and arsenobenzol. Again, patients accept the necessity for investigation of the cerebrospinal fluid, and appear to attend on call when required years later for a lumbar puncture, if a pathological cerebrospinal fluid had been found earlier, even though the patient now called upon felt well and free from symptoms. In conclusion, the success of Scandinavian methods seems to depend, as elsewhere, on three factors: a well-educated and willing patient, an efficient and kindly doctor, and facilities for treatment readily obtained in pleasant and accessible surroundings.

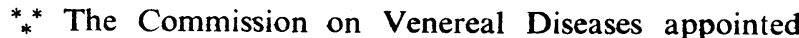
by the Minister of Health in 1937 consisted of Colonel L. W. Harrison and Mr. Dudley C. L. Ward of the Ministry of Health, Dr. T. Ferguson, Deputy Chief Medical Officer of the Department of Health for Scotland, and Dr. Margaret Rorke. Its report, which was published on June 3 by His Majesty's Stationery Office, will receive more detailed notice in a future issue of the Journal.

The jury consisting of Dr. Ch. Achard, Professor Urbain, Professor M. Lisbonne, and Dr. Devraigne, assembled in Paris on May 18, decided that the Prize for Local Immunity shall not be awarded this year. In consequence, its amount will be added to that already in hand, which will thus attain the sum of 30,000 francs. MSS. must reach La Biothérapie, 5, rue Paul-Barruel, Paris, by February 15, 1939, at the latest. 